\title{
Tackling benzodiazepine misuse
}

\author{
(C) $\mathbb{( 1 ) \Theta}$ OPEN ACCESS \\ The time to take decisive action has come
}

\author{
Benedict Hayhoe ${ }^{1}$, James Lee-Davey ${ }^{2}$
}

${ }^{1}$ Department of Primary Care and Public Health, School of Public Health, Imperial College London, UK; ${ }^{2}$ Department of Psychological Medicine, East London NHS Foundation Trust, Royal London Hospital, UK

\begin{abstract}
Discovered in the 1950s by Leo Sternbach, ${ }^{1}$ benzodiazepines were enthusiastically adopted as a safer alternative to barbiturates for management of insomnia and anxiety. Evidence quickly accrued, however, of substantial risk of dependence. Despite recommendation that they be prescribed for no more than four weeks, long term use remains common, with 300000 long term users in the UK. ${ }^{2}$

Benzodiazepines, and the related $\mathrm{z}$ drugs (zopidem, zopiclone, and zalepon), potentiate the rapid neuroinhibitory effect of the neurotransmitter $\gamma$ aminobutyric acid (GABA) in the brain and spinal cord. This results in reduction of anxiety, induction of sleep, and muscle relaxation. Consequently, benzodiazepines are commonly prescribed for anxiety and sleep disorders, but are also highly effective as muscle relaxants; for treating epilepsy, alcohol withdrawal syndrome, and acute behavioural disturbance; and as a premedicant in anaesthesia.

Patients may develop dependence after only a few weeks of regular use and many long term users experience problems on dose reduction, including rebound anxiety, nausea, perceptual changes, and, rarely, epileptic seizures and psychosis. ${ }^{3}$ The muscle relaxant and sedative effects of benzodiazepines increase the risk of falls, particularly in older people, while there is also association with certain infections, and with increased all cause mortality. ${ }^{4}$ In addition to short term amnesic effects, evidence exists of medium and longer term impact on cognition, with an increasingly strong association with dementia. ${ }^{5}$
\end{abstract}

\section{Prescribing and misuse}

Benzodiazepines and $\mathrm{z}$ drugs are commonly misused to help with sleep, relieve stress, and to ameliorate effects of other drugs. In the UK, $7.7 \%$ of respondents admit misuse, comparable with the US, ${ }^{6}$ and misuse by children and young people may be increasing. ${ }^{7}$ Although safer than barbiturates, benzodiazepine overdose can result in coma and death through respiratory depression. Furthermore, the risk of overdose increases substantially when taken with other drugs, especially opiates. ${ }^{8}$

Misused benzodiazepines are usually obtained through diversion from legitimate sources including pharmacies, pharmaceutical suppliers, and prescription. ${ }^{9}$ Higher prescribing rates are associated with increased misuse, ${ }^{10}$ and both benzodiazepines and $\mathrm{z}$ drugs continue to be widely prescribed in UK primary and secondary care. A small decline in the proportion of patients prescribed benzodiazepines in primary care (from $3.5 \%$ in 2000 to $2.6 \%$ in 2016), ${ }^{11}$ was mirrored by a rise in $\mathrm{z}$ drugs, and very long term prescribing is increasing. ${ }^{11}$ Prescribing of benzodiazepines and $\mathrm{z}$ drugs rises with age ${ }^{12}$ and duration of treatment increases with social deprivation ${ }^{11}$; diversion of prescribed drugs may involve exploitation of vulnerable older people and those in financial difficulty. ${ }^{13}$

Growing availability online from unregulated pharmacies and the dark web is concerning, and often involves the significantly more toxic benzodiazepine alprazolam. ${ }^{714}$ Proliferation of private online primary care services may facilitate diversion of prescribed benzodiazepines: visiting multiple doctors is a recognised strategy for obtaining multiple prescriptions for illicit use, ${ }^{9}$ and the Care Quality Commission recently raised concerns about lack of information sharing by online providers in relation to drugs with potential for misuse. ${ }^{15}$

\section{De-prescribing and withdrawal}

Professional guidelines recommend treatment withdrawal for most patients on long term benzodiazepines. ${ }^{16} 17$ This usually takes 3 to12 months or longer, often supported by switching to diazepam, a benzodiazepine whose long half life and availability in various strengths allows gradual dose reduction. However, there is a paucity of evidence for effective interventions to support withdrawal, and a recent review failed to identify evidence of sufficient quality to support any pharmacological interventions. ${ }^{18}$ Psychosocial interventions may be more promising: cognitive behavioural therapy plus tapering is effective in the short term, and relaxation techniques and individualised GP letters to patients can facilitate withdrawal. ${ }^{3}$ However, better evidence is urgently required for both drug and non-drug options. 


\section{Practice and policy}

Benzodiazepines remain important treatments for certain short term indications, but risk of dependence and growing evidence of other harms demand careful consideration as part of shared decisions with patients.

Patients must be fully informed of all risks, and prescribers should follow guidelines on short treatment duration. ${ }^{16}{ }^{17}$ Mechanisms for early review are essential, and clear documentation of intended treatment duration is particularly important at interfaces of care, such as between secondary and primary care. Primary care professionals should conduct active case finding for patients taking benzodiazepines, and follow guidelines on de-prescribing. ${ }^{16}$ Prescribers and pharmacists should also have strict protocols regarding management of lost prescriptions and requests for repeat prescriptions, to avoid fuelling misuse; they should also be alert to the possibility of exploitation of vulnerable patients in diversion of prescribed benzodiazepines. Given the current workload pressures on primary care,${ }^{19}$ however, it is essential that this is supported by sufficient resources, with time and funding for de-prescribing interventions, and access to specialist support.

In January 2018 the Department of Health commissioned an evidence review of dependence on prescribed drugs. ${ }^{20}$ Expected to report early in 2019, it is hoped this will provide further clarity on prescribed benzodiazepine use and misuse in the UK. However, availability of benzodiazepines through unregulated online sources indicate a need for urgent government intervention to tackle misuse of these drugs obtained without a prescription. This should be accompanied by well resourced campaigns to educate the public about the risks of inappropriate benzodiazepine use.

Competing interests We have read and understood BMJ policy on declaration of interests and declare the following interests: none

1 Zhu S, Noviello CM, Teng J, Walsh RMJr, Kim JJ, Hibbs RE. Structure of a human synaptic GABA receptor. Nature 2018;559:67-72. 10.1038/s41586-018-0255-3 29950725

2 Davies J, Rae TC, Montagu L. Long-term benzodiazepine and Z-drugs use in the UK: survey of general practice. Br J Gen Pract 2017;67:e609-13. 10.3399/bjgp17X691865 28716996

3 Darker CD, Sweeney BP, Barry JM, Farrell MF, Donnelly-Swift E. Psychosocial interventions for benzodiazepine harmful use, abuse or dependence. Cochrane Drugs and Alcohol Group, ed. Cochrane Database Syst Rev 2015;11 May. http://doi.wiley.com/ 10.1002/14651858.CD009652.pub2

4 Weich S, Pearce HL, Croft P, et al. Effect of anxiolytic and hypnotic drug prescriptions on mortality hazards: retrospective cohort study. BMJ 2014 19;348:g1996.
5 Penninkilampi R, Eslick GD. A systematic review and meta-analysis of the risk of dementia associated with benzodiazepine use, after controlling for protopathic bias. CNS Drugs 2018;20 June. http://link.springer.com/10.1007/s40263-018-0535-3

6 Kapil V, Green JL, Le Lait C, Wood DM, Dargan PI. Misuse of benzodiazepines and Z-drugs in the UK. Br J Psychiatry 2014;205:407-8. 10.1192/bjp.bp.114.149252 25061118

7 Marsh S. Xanax misuse: doctors warn of "emerging crisis" as UK sales rise. Guardian. 2 May 2018. www.theguardian.com/society/2018/feb/05/xanax-misuse-uk-dark-web-saleshealth.

8 Hernandez I, He M, Brooks MM, Zhang Y. Exposure-response association between concurrent opioid and benzodiazepine use and risk of opioid-related overdose in medicare part $D$ beneficiaries. JAMA Netw Open

2018;1:e18091910.1001/jamanetworkopen.2018.0919

9 Ibañez GE, Levi-Minzi MA, Rigg KK, Mooss AD. Diversion of benzodiazepines through healthcare sources. J Psychoactive Drugs 2013:45:48-56. 10.1080/02791072.2013.764232 23662331

10 Hibell B, Guttormsson U, Ahlström S, et al. The 2011 ESPAD report: substance use among students in 36 European countries. Swedish Council for Information on Alcohol and Other Drugs. 2012. www.espad.org/sites/espad.org/files/The_2011_ESPAD_Report FULL_2012_10_29.pdf.

11 Farias JC, Porter L, McManus S, et al. Prescribing patterns in dependence forming medicines. Public Health Research Consortium; 2017. http://qna.files.parliament.uk/qnaattachments/825285/original/PHRC_014_Final_Report.pdf.

12 Johnson CF, Frei C, Downes N, McTaggart SA, Akram G. Benzodiazepine and z-hypnotic prescribing for older people in primary care: a cross-sectional population-based study. Br J Gen Pract 2016;66:e410-5. 10.3399/bjgp16X685213 27114208

13 Green TC, Bowman SE, Ray M, Zaller N, Heimer R, Case P. Collaboration or coercion? Partnering to divert prescription opioid medications. J Urban Health 2013;90:758-67. 10.1007/s11524-012-9784-5 23371052

14 Isbister GK, O'Regan L, Sibbritt D, Whyte IM. Alprazolam is relatively more toxic than other benzodiazepines in overdose. Br J Clin Pharmacol 2004;58:88-95. 10.1111/j.1365-2125.2004.02089.x 15206998

15 Care Quality Commission. The state of care in independent online primary health services: findings from the CQC's programme of comprehensive inspections in England. 2018. www.cqc.org.uk/sites/default/files/20180322_state-of-care-independent-online-primaryhealth-services.pdf.

16 National Institute of Health and Care Excellence. Clinical knowledge summaries: benzodiazepine and z-drug withdrawal. 2015. https://cks.nice.org.uk/benzodiazepine-andz-drug-withdrawal.

17 Clinical Guidelines on Drug Misuse and Dependence Update 2017 Independent Expert Working Group. Drug misuse and dependence: UK guidelines on clinical management. 2017. https://assets.publishing.service.gov.uk/government/uploads/system/uploads/ attachment_data/file/673978/clinical_guidelines_2017.pdf.

18 Baandrup L, Ebdrup BH, Rasmussen Jø, Lindschou J, Gluud C, Glenthøj BY. Pharmacological interventions for benzodiazepine discontinuation in chronic benzodiazepine users. Cochrane Database Syst Rev 2018:3.CD011481.29543325

19 Hobbs FDR, Bankhead C, Mukhtar T, et alNational Institute for Health Research School for Primary Care Research. Clinical workload in UK primary care: a retrospective analysis of 100 million consultations in England, 2007-14. Lancet 2016;387:2323-30 10.1016/S0140-6736(16)00620-6 27059888

20 Public Health England. Prescribed medicines that may cause dependence or withdrawal: a review of the evidence on the scale and nature of problems with some prescription medicines and how they can be prevented and treated. 2018. www.gov.uk/government/ news/prescribed-medicines-that-may-cause-dependence-or-withdrawal.

Published by the BMJ Publishing Group Limited. For permission to use (where not already granted under a licence) please go to http://group.bmj.com/group/rights-licensing/ permissions This is an Open Access article distributed in accordance with the Creative Commons Attribution Non Commercial (CC BY-NC 4.0) license, which permits others to distribute, remix, adapt, build upon this work non-commercially, and license their derivative works on different terms, provided the original work is properly cited and the use is non-commercial. See: http://creativecommons.org/licenses/by-nc/4.0/. 